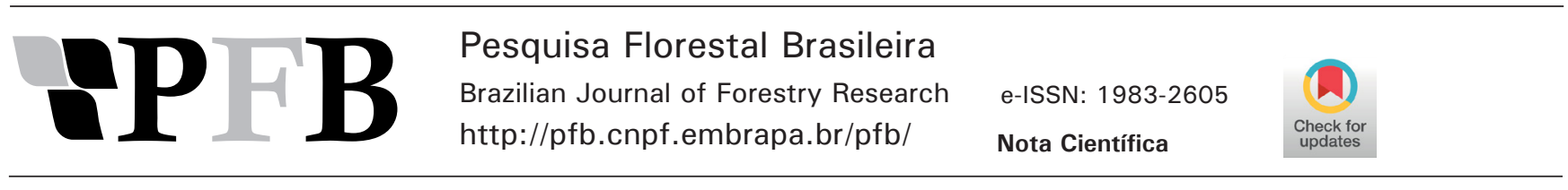

\title{
Aspectos etológicos e reprodutivos de Urbanus velinus (Lepidoptera: Hesperiidae) em borboletário ao ar livre
}

\author{
Henrique Trevisan ${ }^{1}$ (D), Thiago Sampaio de Souza² (D), Acacio Geraldo de Carvalho' ${ }^{\text {(D) }}$ \\ ${ }^{1}$ Universidade Federal Rural do Rio de Janeiro, Departamento de Produtos Florestais, Rodovia BR 465, km 7, CEP 23897-000, Seropédica, RJ, Brasil \\ ${ }^{2}$ Universidade Federal Rural do Rio de Janeiro, Departamento de Fitotecnia, Rodovia BR 465, km 7, CEP 23897-000, Seropédica, RJ, Brasil
}

*Autor correspondente:

thiagosampaio.agro@gmail.com

Termos para indexação:

Comportamento sexual

Clitoria fairchildiana

Ecologia reprodutiva

Index terms:

Sexual behaviour

Clitoria fairchildiana

Reproductive ecology

Histórico do artigo:

Recebido em 04/05/2019

Aprovado em 30/07/2020

Publicado em 30/04/2021

\begin{abstract}
Resumo - Urbanus velinus (Plötz, 1880) é um hesperídio que provoca desfolhamento total de Clitoria fairchildiana. Alguns aspectos envolvendo sua reprodução ainda são uma incógnita para a ciência, incluindo protocolos de reprodução em cativeiro. Com objetivo de obter informações a respeito do seu comportamento sexual e sua ecologia reprodutiva, construiu-se um borboletário onde foram realizadas avaliações diárias durante nove gerações mantidas em cativeiro. Observou-se que por volta do meio-dia inicia-se o processo de corte. $\mathrm{O}$ acasalamento ocorre no período da tarde, cessando no crepúsculo. A reprodução de $U$. velinus em borboletário mostrou-se viável, porém na geração F8 os ovos apresentaram-se inférteis.
\end{abstract}

\section{Ethological and reproductive aspects of Urbanus velinus (Lepidoptera: Hesperiidae) in open-air butterfly}

\begin{abstract}
Urbanus velinus (Plötz, 1880) is a hesperid that causes total defoliation of Clitoria fairchildiana. Some aspects involving their reproduction are still unknown to science, including protocols for captive reproduction. In order to obtain information about their sexual behavior and reproductive ecology, a butterfly house was built where daily assessments were carried out for nine generations kept in captivity. It was observed that around noon the cutting process begins. The mating occurs in the afternoon, ceasing at dusk. The reproduction of $U$. velinus in a butterfly house proved to be viable, however in the F8 generation the eggs were infertile.
\end{abstract}

Urbanus velinus (Plötz, 1880) (Lepidoptera: Hesperiidae), mais conhecido segundo Austin (1998) pela sinonímia $U$. acawoios (Williams, 1926), tem a espécie florestal Clitoria fairchildiana (Fabaceae) como hospedeira típica, a qual, em surtos anuais do inseto, tem a copa desfolhada pela ação das lagartas.

Essa fabácea, embora originária da Região Amazônica, foi introduzida no Sudeste e atualmente é muito empregada na arborização urbana (Lorenzi, 2008). O entendimento da bioecologia desse hesperídio deve ser considerado oportuno, em função da elevada capacidade de desfolha de $U$. velinus nas árvores usadas em áreas urbanas, e também da capacidade de se desenvolver em espécies vegetais com importância econômica, conforme mencionado em diversos estudos (Nadai et al., 2002, 2003; Silva \& Carvalho, 2004; Wendt \& Carvalho, 2006; Trevisan, 2014; Rocha et al, 2019; Santos et al., 2019).

Côrtes et al. (2003) registraram que o ciclo de vida de $U$. velinus varia de 28,7 a 48,6 dias no verão e no inverno, respectivamente, quando alimentado com folhas de C. fairchildiana. As posturas são realizadas em folhas jovens da mesma espécie, sendo o consumo de biomassa 
superior quando tais folhas são ofertadas às lagartas em relação às folhas de maturidade intermediária e mais velhas, porém sem afetar significativamente a duração das fases de larva e pupa (Trevisan et al., 2004). Ainda, sobre o consumo foliar, Nadai et al. (2002) observaram que mais de $80 \%$ ocorre no quarto e quinto instares. Em tais trabalhos, afirma-se que $U$. velinus possui cinco instares larvais, porém Silva \& Carvalho (2004) observaram que ao alimentar lagartas com folhas das leguminosas Desmodum incanum e Galactia striata, ocorre o sexto instar, sugerindo se tratar de alimento menos adequado ao desenvolvimento. Trevisan (2014) alimentou larvas de $U$. velinus com folhas de cultivares de soja transgênica resistente ao herbicida glifosato (Cultivar P98R62) e concluiu que a duração das fases larvais não foi afetada, mas sim a emergência do adulto, com percentual de viabilidade das pupas menor, quando comparado com pupas de lagartas alimentadas com folhas de soja convencional (Cultivar BRS 232).

Apesar da disponibilidade na literatura de trabalhos que avaliam o ciclo biológico de $U$. velinus na geração F0, pesquisas que contemplem sua etologia e ecologia reprodutiva, ou mesmo protocolos de reprodução são inexistentes. Nesse sentido, a observação do horário de liberação de feromônio, acasalamento e atividade de voo são informações fundamentais para o desenvolvimento de técnicas mais eficientes para atrair, capturar e manipular os adultos, visando seu controle (Lingren et al., 1977) ou mesmo para o entendimento de sua bioecologia.

Desta forma, o objetivo deste trabalho foi testar a viabilidade de um protocolo de reprodução de $U$. velinus em cativeiro, descrever o comportamento de corte entre machos e fêmeas, voos de chamamento, caminhamento característico em direção à fêmea, bem como o acasalamento e a oviposição, incluindo o registro dos horários em que ocorrem no decorrer do dia. O trabalho também teve por objetivo determinar a geração populacional de $U$. velinus, em que os ovos apresentam-se inférteis, após sucessivos cruzamentos entre indivíduos consanguíneos.

O experimento foi realizado no município de Seropédica, RJ, no Laboratório de Entomologia Florestal do Departamento de Produtos Florestais do campus da Universidade Federal Rural do Rio de Janeiro. Foi construída uma gaiola telada com sombrite $50 \%$ (borboletário), ao ar livre, de $4 \mathrm{~m} \mathrm{x} 4 \mathrm{~m}$ x $3 \mathrm{~m}$ (largura $\mathrm{x}$ comprimento $\mathrm{x}$ altura), com estrutura de madeira com
5 pernas de três com $8 \mathrm{~cm} \times 8 \mathrm{~cm} \times 1,40 \mathrm{~m}$ cada. No teto da gaiola foram colocados 12 pregadores de plástico, distribuídos uniformemente, de forma que ficassem pendurados por um fio de nylon medindo $50 \mathrm{~cm}$. Nesses foram alocados chumaços de algodão embebidos com água e mel a 10\%, como alimento ofertado aos adultos. No solo da gaiola foram plantadas 8 mudas de $C$. fairchildiana para oviposição.

Ovos de U. velinus que viabilizaram a criação foram coletados em condições de campo, em folhas de $C$. fairchildiana, e levados ao laboratório. Após a eclosão, as lagartas foram criadas até empuparem. Após a sexagem das pupas, estas foram acomodadas dentro do

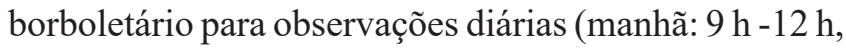
tarde: 13:00-16:30 h e noite: $18-21 \mathrm{~h}$ ), com o objetivo de descrever a ecologia reprodutiva de $U$. velinus durante nove gerações do inseto.

Os parâmetros observados e descritos foram: comportamento dos machos na presença das fêmeas na gaiola, como excitamento e movimentos a partir do toque na fonte (fêmea); vôos de chamamento; caminhamento característico em direção à fêmea; corte, acasalamento e oviposição. Também foi registrado o momento em que os ovos se mostraram inférteis pela ação da endogamia da população.

Constatou-se que $U$. velinus tem hábitos reprodutivos diurnos. Na escotofase não há atividade relacionada à reprodução, sendo espécie exclusivamente relacionada com a fase clara. Observou-se uma forte influência da temperatura nos hábitos sexuais. O comportamento de corte, durante as observações realizadas em oito gerações populacionais, demonstrou ocorrer mais intensamente no momento mais quente do dia, ou seja, por volta do meio dia.

Esse comportamento perdurava até por volta das $17 \mathrm{~h}$, sendo cessado, por completo, no crepúsculo. O acasalamento foi notado com maior intensidade na parte da tarde, por volta das $14 \mathrm{~h}$ às $16 \mathrm{~h}$. Em dias considerados frios (temperatura média entre 18 e $24{ }^{\circ} \mathrm{C}$ ), observouse a permanência dos adultos pousados na vegetação, sem atividade. Nesse contexto, Vilela \& Lucia (1987) afirmam que existem interações entre a temperatura, o fotoperíodo e o ritmo do inseto para a liberação dos feromônios sexuais. Portanto, a temperatura e o fotoperíodo podem estar relacionados com as observações realizadas nesse trabalho. Ainda, o início do processo de corte foi notado após três dias do começo das emergências, sugerindo que o amadurecimento de 
processos fisiológicos relativos à maturidade sexual de $U$. velinus, ocorreu após esse período.

Registrou-se que entre três e quatro machos perseguem uma única fêmea. O acasalamento só acontecia quando essa perseguição ficava restrita a um único casal, e estes voos, passavam de lineares e velozes lentos e em ziguezague, onde macho e fêmea se alternavam um em frente ao outro em voos verticais. A cópula ocorria quando a fêmea pousava em um suporte, geralmente a vegetação, e o macho pousava ao lado. Este, estando posicionado lateralmente à fêmea, curvava o abdome em direção ao órgão sexual da fêmea e, com o abdome curvado e as asas fechadas, se direcionava, caminhando lateralmente e para trás para o acoplamento, onde a fêmea realizava aceitação e a cópula era realizada. $O$ tempo médio da cópula, obtido pela observação de dez casais, foi de 60 $\pm 18 \mathrm{~min}$, com as caudas cruzadas para um único lado (Figura 1).

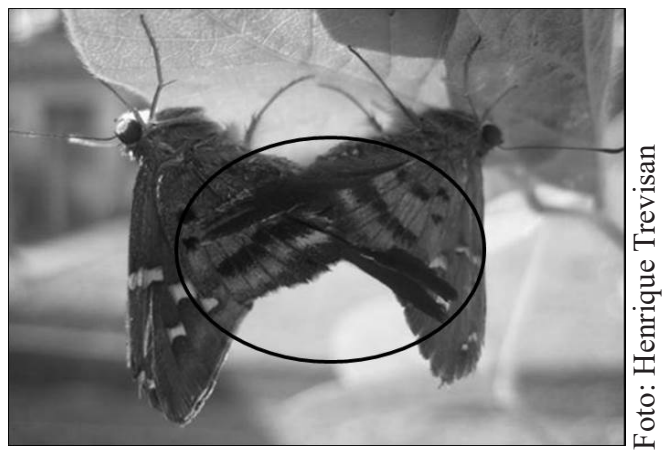

Figura 1. Cópula de Urbanus velinus, detalhe da cauda cruzada para um mesmo lado.

Figure 1. Copulation of Urbanus velinus, detail of the tail crossed to the same side.

O início da oviposição pela fêmea de U. vellinus se deu pela antenação de folhas jovens de $C$. fairchildiana, ocorrendo sempre na parte da tarde, entre 14-16 h. Nesse contexto, características físicas do vegetal podem influenciar esse comportamento. Calatayud et al. (2008) observaram em uma espécie de Noctuidae, que o diâmetro, pubescência e rugosidade do substrato vegetal têm influência na oviposição deste Lepidoptera. Segundo Prokopy et al. (1984), a localização de potenciais recursos se dá, sobretudo, pela presença de compostos químicos derivados dos mesmos.

Portanto, o reconhecimento do sítio de oviposição por parte da fêmea de $U$. velinus pode estar relacionado com os conceitos sugerido por Prokopy et al. (1984) e por Calatayud et al. (2008). Sendo assim, entende-se que o ato de promover a antenação na folha, trata-se da procura de sítios adequados à oviposição, e este comportamento pode estar associado a uma avaliação tanto das características físicas do substrato, como dos compostos químicos provindos do hospedeiro, no caso, folhas jovens de $C$. fairchildiana. Sobre essa hipótese, Hamidi \& Frérot (2016), estudando a oviposição de Paysandisia archon (Lepidoptera: Castniidae), também relataram que os odores provindos do vegetal desempenharam papel fundamental na atração da fêmea e esta, segundo esses autores, realiza a antenação do substrato para avaliá-lo tanto física como quimicamente.

Assim que o substrato foi reconhecido, a fêmea colocou-se em um plano superior na folha, curvou seu abdome e iniciou um movimento de "sobe e desce" com o mesmo, em direção ao substrato. Este movimento foi cessado quando se iniciou a colocação de cada ovo, momento em que o abdome permaneceu imóvel, até que o ovo tivesse aderido à folha. Este processo foi realizado até que todos os ovos fossem ovipositados, definindo o final da postura, que foi caracterizado com um voo pós-postura. A população de $U$. velinus foi mantida em cativeiro até a geração $F 8$, fase na qual todos os ovos gerados apresentaram-se inférteis (Figura 2). Possivelmente, a infertilidade dos ovos foi resultado de cruzamentos sucessivos entre indivíduos consanguíneos.

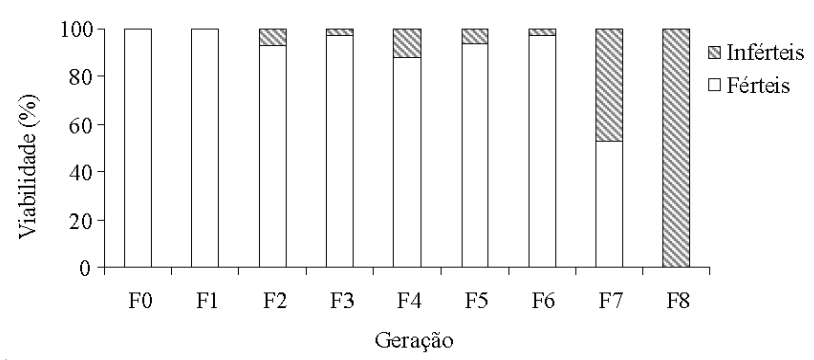

Figura 2. Viabilidade de ovos de Urbanus velinus mantido em cativeiro entre a geração F0 a F8.

Figure 2. Viability of Urbanus velinus eggs kept in captivity between $\mathrm{F} 0$ and $\mathrm{F} 8$ generation.

\section{Conclusões}

Urbanus velinus se reproduz em borboletário implantado ao ar livre e a população se mantem com cruzamentos viáveis, com fêmeas produzindo ovos férteis até a sétima geração, resultando na total inviabilidade na geração posterior. $U$. velinus tem hábitos reprodutivos exclusivamente associados à fase 
clara, apresentando evidências de que a temperatura ambiente tem influência nos comportamentos de corte e acasalamento. Esses são estimulados em dias e nos horários mais quentes, sendo inibidos ou cessados por completo em dias frios.

O processo de corte de U. velinus inicia-se após três dias da emergência dos adultos, indicando que a maturidade sexual se dá após esse período.

A fêmea de $U$. velinus realiza postura em folhas jovens de Clitoria fairchildiana. Antes de iniciar essa ação, promove a antenação desse substrato, sinalizando tratarse de comportamento associado à procura de estímulos químicos e físicos do hospedeiro.

\section{Referência}

Austin, G. T. Hesperiidae of Rondônia Brazil: Ridens and the "Proteus" group of Urbanus, with descriptions of new species (Pyrginae). Journal of the Lepidopterists Society, v. 52, n. 2, p. 166-176, 1998.

Calatayud, P.-A. et al. Importance of plant physical cues in host acceptance for oviposition by Busseola fusca. Entomologia Experimentalis et Applicata, v. 126, n. 3, p. 233-243, 2008. https:// doi.org/10.1111/j.1570-7458.2007.00660.x.

Côrtes, M. S. et al. Influência de diferentes condições climáticas nos parâmetros biológicos de Urbanus acawoios (Lepidoptera; Hesperidae) alimentados com folíolos de Clitoria fairchildiana. Revista Universidade Rural, v. 23, n. 2, p. 107-111, 2003.

Hamidi, R. \& Frérot, B. Oviposition behaviour in Paysandisia archon (Lepidoptera: Castniidae). Annales de la Société Entomologique de France, v. 52, n. 3, p. 167-170, 2016. https://doi.org/10.1080/0 0379271.2016.1226148.

Lingren, P. D. et al. Nocturnal behavior of four lepidopteran pest that attack tobacco and other crops. Annals of the Entomological Society of America, v. 70, p. 161-167, 1977. https://doi.org/10.1093/ aesa/70.2.161.
Lorenzi, H. Árvores brasileiras: manual de identificação e cultivo de plantas arbóreas nativas do Brasil. 5. ed. Nova Odessa: Instituto Plantarum, 2008. v. 1.384 p.

Nadai, J. de et al. Consumo de área foliar de Urbanus acawoios (Lepidoptera: Hesperiidae) em feijão vermelho (Phaseolus vulgares). Revista Universidade Rural, v. 22, n. 2, p. 137-140, 2002.

Nadai, J. de et al. Desenvolvimento de Urbanus acawoios (Williams, 1926) (Lepidoptera: Hesperridae), praga em arborização urbana, em duas cultiraves de feijoeiro (Phaseolus vulgaris L.). Biotemas, v. 16, n. 2, p. 77-88, 2003.

Prokopy, R. J. et al. Resource partitioning. In: Bell, J. \& Cardé, R. T. (ed.). Chemical Ecology of insects. London: Chapman \& Hall, 1984. p 301-330.

Rocha, C. V. S. et al. Análise da influência de sete genótipos de Fabaceae sobre a duração e mortalidade da fase larval de Urbanus velinus (Plötz, 1880) (Lepidoptera: Hesperiidae).In: Simpósio de Fitossanidade e Biotecnologia Aplicada, 5., 2019, Seropédica. Resumos [...]. Seropédica: UFRRJ, 2019. p. 12.

Santos, C. A. A. et al. Primeiro registro de Canavalia ensiformis e Phaseolus lunatus como planta hospedeira de Urbanus velinus (Lepidoptera: Hesperiidae). In: Simpósio Internacional de Entomologia, 6., 2019, Viçosa, MG. Anais [...]. Viçosa, MG: UFV, 2019. p. 1.

Silva, E. de J. \& Carvalho, A. G. de. Influencia de Clitoria fairchildiana, Desmodium incanum e Galactia striata (Leguminosae) na biologia de Urbanus acawoios (Lepidoptera: Hesperiidae). Quebracho, v. 11, p. 33-41, 2004.

Trevisan, H. et al. Consumo foliar e aspectos biológicos de Urbanus acawoios (Lep.: Hesperiidae) alimentado com folíolos de Clitoria fairchildiana (Leguminosae: Faboideae) em três níveis de maturidade. Ciência Rural, v. 34, n. 1, p. 1-4, 2004. https://doi. org/10.1590/S0103-84782004000100001.

Trevisan, H. Avaliação do efeito de plantas transgênicas em Lepidoptera: análises da influência da soja RR na biologia de Urbanus acawoios e do pólen do milho Bt em Galleria mellonella. Beau Bassin: Novas Edições Acadêmicas, 2014. 116 p.

Vilela, E. F. \& Lucia, T. M. C. D. Feromônios de insetos. Viçosa, MG: UFV, 1987. 155 p.

Wendt, J. G. N. \& Carvalho, A. G. Consumo foliar de Phaseolus vulgaris L. (Leguminoseae) por Urbanus acawoios Willians, 1926 (Lepidoptera: Hesperiidae). Biotemas, v. 19, n. 1, p. 19-23, 2006. 